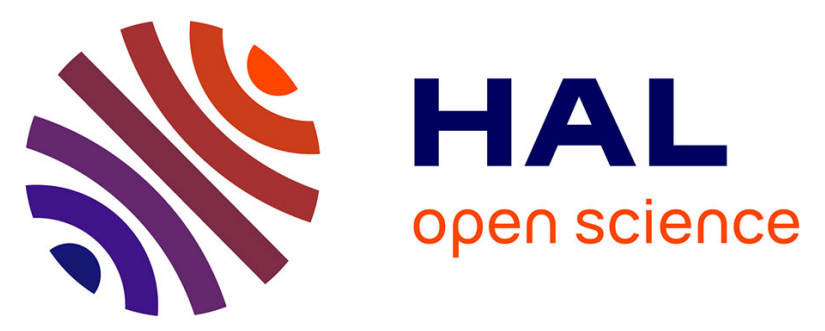

\title{
Clay minerals for the removal of pharmaceuticals: Initial investigations of their adsorption properties in real wastewater effluents
}

\author{
Thomas Thiebault, Mohammed Boussafir, Laëtitia Fougère, Emilie
}

Destandau, Lucie Monnin, Claude Le Milbeau

\section{To cite this version:}

Thomas Thiebault, Mohammed Boussafir, Laëtitia Fougère, Emilie Destandau, Lucie Monnin, et al.. Clay minerals for the removal of pharmaceuticals: Initial investigations of their adsorption properties in real wastewater effluents. Environmental Nanotechnology, Monitoring \& Management, 2019, 12 (100266), 6 p. 10.1016/j.enmm.2019.100266 . insu-02324628

\section{HAL Id: insu-02324628 \\ https://hal-insu.archives-ouvertes.fr/insu-02324628}

Submitted on 22 Oct 2019

HAL is a multi-disciplinary open access archive for the deposit and dissemination of scientific research documents, whether they are published or not. The documents may come from teaching and research institutions in France or abroad, or from public or private research centers.
L'archive ouverte pluridisciplinaire HAL, est destinée au dépôt et à la diffusion de documents scientifiques de niveau recherche, publiés ou non, émanant des établissements d'enseignement et de recherche français ou étrangers, des laboratoires publics ou privés. 
4 Thomas Thiebault ${ }^{\mathrm{a}, b^{*}}$, Mohammed Boussafir ${ }^{\mathrm{a}}$, Laëtitia Fougère ${ }^{\mathrm{c}}$, Emilie Destandau ${ }^{\mathrm{c}}$, Lucie

$5 \quad$ Monnin $^{\mathrm{a}}$ and Claude Le Milbeau ${ }^{\mathrm{a}}$

6 anstitut des Sciences de la Terre d'Orléans, UMR 7327, Univ Orleans, CNRS, BRGM, 45071

7 Orleans, France

8 bPHE, PSL University, UMR 7619 METIS (SU, CNRS, EPHE), 4 place Jussieu, F-75005,

9 Paris, France

$10{ }^{\mathrm{c} U n i v}$ Orleans, CNRS, ICOA, UMR 7311, 45067 Orleans, France

11 *To whom correspondence should be addressed. E-mail: thomas.thiebault@ephe.psl.eu Phone:

$12+33(0) 144275997$

\section{Abstract}

14 The adsorption of pharmaceutical products (PPs) onto kaolinite and raw and sodium-exchanged

15 montmorillonite was investigated in real wastewater effluents (WWE). The important role of the

16 charge state of the PPs in controlling the adsorption extent was highlighted. Whereas cationic PPs

17 were mostly adsorbed through cation exchange, the adsorption of neutral and anionic PPs appeared

18 to be controlled by the nature of compensating inorganic cations and/or the simultaneous

19 adsorption of organic moieties onto clay minerals. In raw WWE, the concentration of PPs is indeed

20 far lower than the concentration of other organic molecules. Among the adsorbents tested, kaolinite

21 displayed the lowest adsorption capacity of both PPs and other organic molecules, compared to

22 raw montmorillonite which presented the highest adsorption capacity. The sodium-exchanged

23 montmorillonite displayed intermediate adsorption properties, highlighting the key role of divalent

24 inorganic cations in the adsorption of non-cationic PPs and other organic molecules. Hence, raw 
25 montmorillonite appears to be the most promising adsorbent for further investigations aiming to

26 test the practicability of a clay-based adsorbent for the removal of organic contaminants, such as

27 PPs, in WWE.

28 Keywords

29 Pharmaceutical Products, Clay minerals, Adsorption, Wastewater Treatment, Organic Matter

$30 \quad$ 1. Introduction

31 The occurrence of pharmaceutical products (PPs) in numerous environmental compartments (da

32 Silva et al., 2011; Patel et al., 2019) raises serious concerns about their potential hazard for living

33 organisms (Richmond et al., 2018; Saaristo et al., 2018). Contamination by PPs is mostly generated

34 by excretion through urine and feces following both human and veterinary uses (Baker et al., 2014;

35 Choi et al., 2018). Then, PP-contaminated wastewaters are transferred toward wastewater treatment

36 plants, in which current treatment chains remain inappropriate for their complete removal

37 (Grandclément et al., 2017; Petrie et al., 2015). This contamination therefore challenges the

38 scientific community and water treatment operators in order to find efficient and economically

39 practicable removal solutions. Among the innovative treatments for the removal of organic

40 contaminants, adsorption is considered as a promising way if the selected adsorbent displays a high

41 adsorption capacity and moderate cost (de Andrade et al., 2018). Most of the literature focuses on

42 activated carbons, which are currently used for the treatment of drinking water (Cuthbertson et al.,

43 2019; Wong et al., 2018), even though the potential of clay minerals for the removal of organic

44 contaminants has already been demonstrated (Thiebault, 2019; Zhu et al., 2016). Moreover, clay

45 minerals can be considered as cheap and widely available materials. Yet, several studies pointed

46 out their limitations for the adsorption of non-cationic PPs (Gao and Pedersen, 2005; Zhang et al.,

47 2010). These limitations, however, were mostly found during batch experiments, in which the 
starting concentration of PPs wase much higher than their environmental occurrences, and in

49 idealized solutions (i.e. pure water, no competing compounds). Several studies have recently

50 demonstrated that the affinity of anionic and neutral PPs with clay minerals can be improved in the

51 presence of other organic moieties (de Oliveira et al., 2017; Wu et al., 2019). Therefore, it appears

52 necessary to assess as precisely as possible the potential of a clay-based solution for the removal

53 of PPs in real WWE in order to determine the affinity of such contaminants with adsorbents and to

54 evaluate which type of clay minerals would be the most versatile for the design of a removal

55 solution. The purpose of this work was therefore to investigate the PP removal potential of three

56 clay minerals in raw WWE.

\section{Material and methods}

\subsection{Chemical reagents and adsorbents}

59 Standards for atenolol (ATE), bezafibrate (BZB), carbamazepine (CBZ), codeine (COD),

60 diazepam (DIA), diclofenac (DCF), doxepin (DOX), gemfibrozil (GEM), ketoprofen (KET),

61 naproxen (NAP), metoprolol (MET), norfloxacin (NOR), oxazepam (OXA), sulfamethoxazole

62 (SUL), tramadol (TRA) and trimethoprim (TMP) were purchased from Sigma-Aldrich with a

63 purity $>98 \%$. Separation solvents, methanol $(\mathrm{MeOH})$ and acetonitrile $(\mathrm{AcN})$ were purchased from

64 Fisher-Scientific, assuming an analytical grade (purity higher than $99.95 \%$ ).

65 Table 1: Physico-chemical properties of the targeted PPs, with Abb. the abbreviation, $\mathrm{M}_{\mathrm{w}}$ the molecular 66 weight in $\mathrm{g} \cdot \mathrm{mol}^{-1}, \mathrm{pK}_{\mathrm{a}}$ the acid dissociation constant, $\log \mathrm{K}_{\mathrm{ow}}$ the octanol/water partition coefficient, $\mathrm{S}_{\mathrm{w}}$ the 67 solubility in water at $25^{\circ} \mathrm{C}$ in $\mathrm{mg} . \mathrm{L}^{-1}$, and Charge the dominant form at the effluent $\mathrm{pH}(\mathrm{i} . \mathrm{e} .=6.4$ )

\begin{tabular}{|c|c|c|c|c|c|c|c|c|}
\hline PP & Abb. & Formula & CAS-Number & $\mathbf{M}_{w}$ & $\mathrm{pK}_{\mathrm{a}}^{\mathrm{a}}$ & $\log K_{\text {ow }}{ }^{b}$ & $S_{w}{ }^{a}$ & Charge \\
\hline Atenolol & ATE & $\mathrm{C}_{14} \mathrm{H}_{22} \mathrm{~N}_{2} \mathrm{O}_{3}$ & $29122-68-7$ & 266.3 & 9.6 & 0.16 & 430 & + \\
\hline Bezafibrate & $\mathrm{BZB}$ & $\mathrm{C}_{19} \mathrm{H}_{20} \mathrm{ClNO}_{4}$ & $41859-67-0$ & 361.8 & 3.9 & 4.25 & 1.5 & - \\
\hline Carbamazepine & $\mathrm{CBZ}$ & $\mathrm{C}_{15} \mathrm{H}_{12} \mathrm{~N}_{2} \mathrm{O}$ & $298-46-4$ & 236.3 & 13.9 & 2.45 & 152 & 0 \\
\hline Codeine & COD & $\mathrm{C}_{18} \mathrm{H}_{21} \mathrm{NO}_{3}$ & $76-57-3$ & 299.4 & 8.2 & 1.28 & 577 & + \\
\hline Diazepam & DIA & $\mathrm{C}_{16} \mathrm{H}_{13} \mathrm{ClN}_{2} \mathrm{O}$ & $439-14-5$ & 284.7 & 3.4 & 2.70 & 50 & 0 \\
\hline Diclofenac & $\mathrm{DCF}$ & $\mathrm{C}_{14} \mathrm{H}_{11} \mathrm{Cl}_{2} \mathrm{NO}_{2}$ & $15307-79-6$ & 296.1 & 4.2 & 4.02 & 4.5 & - \\
\hline Doxepin & DOX & $\mathrm{C}_{19} \mathrm{H}_{21} \mathrm{NO}$ & $1229-29-4$ & 279.4 & 9.0 & 3.86 & 32 & + \\
\hline Gemfibrozil & GEM & $\mathrm{C}_{15} \mathrm{H}_{22} \mathrm{O}_{3}$ & $25812-30-0$ & 250.3 & 4.8 & 4.33 & 28 & - \\
\hline Ketoprofen & KET & $\mathrm{C}_{16} \mathrm{H}_{14} \mathrm{O}_{3}$ & $22071-45-4$ & 254.3 & 4.4 & 3.00 & 21 & - \\
\hline Metoprolol & MET & $\mathrm{C}_{15} \mathrm{H}_{25} \mathrm{NO}_{3}$ & $56392-17-7$ & 267.4 & 9.6 & 1.69 & 502 & + \\
\hline Naproxen & NAP & $\mathrm{C}_{14} \mathrm{H}_{14} \mathrm{O}_{3}$ & 22204-53-1 & 230.3 & 4.2 & 3.10 & 16 & - \\
\hline
\end{tabular}




\begin{tabular}{lllrlrrrr}
\hline Norfloxacin & NOR & $\mathrm{C}_{16} \mathrm{H}_{18} \mathrm{FN}_{3} \mathrm{O}_{3}$ & $70458-96-7$ & 319.3 & $5.7-8.7$ & -0.31 & 1,010 & $+/-$ \\
Oxazepam & OXA & $\mathrm{C}_{15} \mathrm{H}_{11} \mathrm{ClN}_{2} \mathrm{O}_{2}$ & $604-75-1$ & 287.0 & $1.7-11.6$ & 3.34 & 88 & 0 \\
Sulfamethoxazole & SUL & $\mathrm{C}_{10} \mathrm{H}_{11} \mathrm{~N}_{3} \mathrm{O}_{3} \mathrm{~S}$ & $723-46-6$ & 253.3 & 6.2 & 0.48 & 459 & - \\
Tramadol & TRA & $\mathrm{C}_{16} \mathrm{H}_{25} \mathrm{NO}_{2}$ & $27203-92-5$ & 263.4 & 9.4 & 3.01 & 750 & + \\
Trimethoprim & TMP & $\mathrm{C}_{14} \mathrm{H}_{18} \mathrm{~N}_{4} \mathrm{O}_{3}$ & $738-70-5$ & 290.3 & 7.2 & 0.73 & 615 & $+/ 0$ \\
\hline
\end{tabular}

With ${ }^{\mathrm{a}}$ drugbank.ca and ${ }^{\mathrm{b}}$ chemspider.com (predicted KOWWIN v.1.67)

The selected adsorbents were Georgia kaolinite KGa-2 and Wyoming smectite SWy-2 both

two adsorbents were fractionated $<2 \mu \mathrm{m}$ by gravity sedimentation prior to use in order to limit the

73 impact of mineralogical impurities (Chipera and Bish, 2001). In order to investigate the impact of

74 compensating inorganic cations on the removal capacity of SWy-2, this adsorbent was used raw

$75\left(\sim 20 \%\right.$ of $\mathrm{Ca}^{2+}$ and $80 \%$ of $\left.\mathrm{Na}^{+}\right)$and $\mathrm{Na}$-exchanged through well-established procedures (Le

76 Forestier et al., 2010).

77 The resulting materials, labelled $\mathrm{KGa} 2, \mathrm{SWy} 2$ and $\mathrm{Na}-\mathrm{SWy} 2$ display a cation exchange capacity

78 of $3.7,85$ and 85 meq. $100 \mathrm{~g}^{-1}$ respectively, and a specific surface area of 18,32 and $32 \mathrm{~m}^{2} \cdot \mathrm{g}^{-1}$

79 respectively with the $\mathrm{N}_{2}$ BET method (Le Forestier et al., 2010; Lv et al., 2013).

\subsection{Sample collection and batch experiments}

$8110 \mathrm{~L}$ of WWE were sampled at the outlet of a vertical-flow constructed wetland in one intake

82 (central part of France). The design of this sewage treatment plant consists of two stages of

83 unsaturated vertical-flow constructed wetlands in series, with the first one planted with Phragmites

84 Australis (Paing and Voisin, 2005). After collection, WWE were filtered with glass-fiber filters

85 (GF/F, Whatman) prior to storage at $4^{\circ} \mathrm{C}$ in amber glass bottles.

86 Batch experiments were systematically conducted in triplicate on the day following the sampling.

87 The WWE solutions (200 mL) were put in $250 \mathrm{~mL}$ bottles, mixed with 100 or $200 \mathrm{mg}$ of adsorbents

88 (i.e. KGa2, Na-SWy2 and SWy2) and then wrapped in aluminum foil in order to prevent light-

89 induced degradation. The solutions were stirred for 2 hours at $500 \mathrm{rpm}$ with a magnetic stirrer. This 
90 time was considered as appropriate to reach equilibrium in such conditions (Thiebault et al.,

91 2016a). A volume of $100 \mathrm{~mL}$ of supernatant was recovered by centrifugation at 8,000 rpm during

9210 minutes prior to the extraction and analysis of the PPs. In parallel, blank experiments (i.e. Blank)

93 were conducted in the same conditions without adsorbent, in order to estimate the initial PP

94 concentration and avoid any misinterpretation due to degradation.

\section{$95 \quad$ 2.3.Quantification and validation}

96 The quantification procedure of PPs, and its validation, were already presented in detail (Thiebault

97 et al., 2019). Briefly, a solid phase extraction was performed on the supernatant using Chromabond

98 HR-X cartridges (6 mL x $500 \mathrm{mg}$, Macherey-Nagel) prior to analysis and quantification in high

99 pressure liquid chromatography coupled with tandem mass spectrometry. The equipment,

100 analytical procedures and quantification performances are detailed in the supplementary material

101 (Table S1-2).

$102 \quad$ 2.4.Processing of the results and analysis of the adsorbents

103 The removal of PPs after interaction was calculated using the following equation:

$$
\text { Removal }=100-\left(\frac{100 \times C_{e q}}{C_{s t}}\right)
$$

105 with the Removal in $\%, \mathrm{C}_{\text {eq }}$ the equilibrium concentration in $\mu \mathrm{g} . \mathrm{L}^{-1}$ and $\mathrm{C}_{\text {st }}$ the starting 106 concentration in $\mu \mathrm{g} . \mathrm{L}^{-1}$

107 In order to evaluate the amount of organic matter adsorbed onto the clay minerals after interaction, 108 carbon analyses were performed on powdered samples by using a Thermo Scientific Flash 2000

109 organic analyzer. These analyses were systematically triplicated. XRD and FTIR analysis

110 conditions are given in the supplementary material.

\section{3. Results and Discussion}


113 The concentrations of PPs and the physico-chemical characterization of the raw WWE were

114 determined in triplicate experiments. The most concentrated PPs were TRA and DCF with

115 concentrations of 12.48 and $8.23 \mu \mathrm{g} . \mathrm{L}^{-1}$, respectively. The concentrations of the other PPs mostly

116 ranged between 0.03 and $1.32 \mu \mathrm{g} . \mathrm{L}^{-1}$ (Table 2).

117 The analysis of the WWE provided the following values: $\mathrm{pH}=6.4$, Total Organic Carbon content

118 was 27.6 mg.L ${ }^{-1}$, P-PO 4 content was 12.0 mg.L ${ }^{-1}$, N-NO 2 content was 59.2 mg.L ${ }^{-1}$, Suspended

119 solids concentration was $5 \mathrm{mg} . \mathrm{L}^{-1}$ and the conductivity was $950 \mu \mathrm{S} . \mathrm{cm}^{-1}$.

120 Table 2: Concentrations of the targeted PPs (in $\mu \mathrm{g} . \mathrm{L}^{-1}$ ) in the raw effluent (Blank) and after interaction with 121 100 and $200 \mathrm{mg}$ of the selected clay minerals, with LOD the limit of detection

\begin{tabular}{lccccccc}
\hline \multirow{2}{*}{ PP } & \multirow{2}{*}{ Blank } & \multicolumn{2}{c}{ KGa2 } & \multicolumn{2}{c}{ Na-SWy2 } & \multicolumn{2}{c}{ SWy2 } \\
\cline { 2 - 7 } & & $\mathbf{1 0 0 m g}$ & $\mathbf{2 0 0 m g}$ & $\mathbf{1 0 0 m g}$ & $\mathbf{2 0 0 m g}$ & $\mathbf{1 0 0 m g}$ & $\mathbf{2 0 0 m g}$ \\
\hline ATE & $0.55 \pm 0.10$ & $0.52 \pm 0.16$ & $0.46 \pm 0.10$ & $0.40 \pm 0.13$ & $0.25 \pm 0.00$ & $0.42 \pm 0.15$ & $0.23 \pm 0.10$ \\
BZF & $0.19 \pm 0.08$ & $0.14 \pm 0.03$ & $0.13 \pm 0.04$ & $0.12 \pm 0.06$ & $0.14 \pm 0.09$ & $0.11 \pm 0.05$ & $0.05 \pm 0.01$ \\
CBZ & $0.34 \pm 0.03$ & $0.34 \pm 0.04$ & $0.33 \pm 0.04$ & $0.33 \pm 0.03$ & $0.34 \pm 0.02$ & $0.31 \pm 0.06$ & $0.31 \pm 0.07$ \\
COD & $0.03 \pm 0.01$ & $0.02 \pm 0.01$ & $0.01 \pm 0.00$ & $0.00 \pm 0.01$ & $<$ LOD & $0.00 \pm 0.00$ & $0.00 \pm 0.00$ \\
DIA & $0.03 \pm 0.00$ & $0.03 \pm 0.00$ & $0.03 \pm 0.01$ & $0.02 \pm 0.01$ & $0.02 \pm 0.01$ & $0.02 \pm 0.01$ & $0.01 \pm 0.01$ \\
DCF & $8.23 \pm 1.69$ & $7.46 \pm 0.86$ & $6.87 \pm 1.59$ & $8.05 \pm 0.59$ & $7.84 \pm 1.99$ & $6.91 \pm 0.50$ & $5.19 \pm 0.42$ \\
DOX & $0.84 \pm 0.09$ & $0.80 \pm 0.08$ & $0.67 \pm 0.36$ & $0.74 \pm 0.26$ & $0.30 \pm 0.07$ & $0.50 \pm 0.41$ & $0.07 \pm 0.02$ \\
GEM & $0.06 \pm 0.02$ & $0.06 \pm 0.01$ & $0.06 \pm 0.02$ & $0.06 \pm 0.02$ & $0.05 \pm 0.01$ & $0.05 \pm 0.03$ & $0.03 \pm 0.01$ \\
KET & $0.62 \pm 0.04$ & $0.58 \pm 0.09$ & $0.53 \pm 0.11$ & $0.58 \pm 0.04$ & $0.53 \pm 0.14$ & $0.51 \pm 0.06$ & $0.20 \pm 0.16$ \\
MET & $0.07 \pm 0.03$ & $0.06 \pm 0.01$ & $0.05 \pm 0.02$ & $0.04 \pm 0.01$ & $0.03 \pm 0.02$ & $0.05 \pm 0.01$ & $0.03 \pm 0.01$ \\
NAP & $1.32 \pm 0.10$ & $1.43 \pm 0.31$ & $1.35 \pm 0.31$ & $1.38 \pm 0.18$ & $1.13 \pm 0.87$ & $1.16 \pm 0.15$ & $0.58 \pm 0.26$ \\
NOR & $0.92 \pm 0.78$ & $0.03 \pm 0.03$ & $<$ LOD & $0.12 \pm 0.21$ & $<$ LOD & $0.28 \pm 0.49$ & $<$ LOD \\
OXA & $0.16 \pm 0.01$ & $0.15 \pm 0.01$ & $0.14 \pm 0.03$ & $0.15 \pm 0.02$ & $0.15 \pm 0.03$ & $0.14 \pm 0.01$ & $0.12 \pm 0.03$ \\
SUL & $0.00 \pm 0.01$ & $<$ LOD & $<$ LOD & $<$ LOD & $<$ LOD & $<$ LOD & $<$ LOD \\
TRA & $12.48 \pm 1.04$ & $11.55 \pm 0.61$ & $10.6 \pm 2.11$ & $2.83 \pm 1.35$ & $2.87 \pm 0.46$ & $8.37 \pm 7.78$ & $3.47 \pm 4.30$ \\
TMP & $0.05 \pm 0.02$ & $0.05 \pm 0.03$ & $0.05 \pm 0.04$ & $0.03 \pm 0.02$ & $0.03 \pm 0.01$ & $0.04 \pm 0.04$ & $0.02 \pm 0.01$ \\
\hline
\end{tabular}

\subsection{Removal of PPs from wastewater effluents}

124 Due to the important role of the speciation on the affinity between PPs and clay minerals, the

125 removal values after interaction with clay minerals are hereafter detailed according to the

126 theoretical speciation of the PPs (Table 1).

\subsubsection{Positively charged PPs}

128 The removal values of cationic and zwitterionic PPs are presented in Figure 1. Except for NOR, 129 which shows a high removal rate whatever the adsorbent, the removal rates of cationic PPs display 
130 the same pattern. The removal is lower after interaction with $\mathrm{KGa}$, whereas very similar removal

131 values are found for SWy2 and Na-SWy2. Moreover, increasing the mass of adsorbent increases

132 the removal values of PPs (Figure 1). In general, with $200 \mathrm{mg}$ of montmorillonite, the removal rate

133 ranges from 58 to $100 \%$. Yet, for several cationic PPs such as DOX and TRA, it was expected that

134 this removal would be total within this range of concentration due to the high affinity between these

135 PPs and clay minerals, and the adsorption through cation exchange (Chen et al., 2010; Thiebault et

136 al., 2015). However, the complexity of WWE (e.g. inorganic and organic compounds) associated

137 with the low starting concentration of PPs in comparison to total organic carbon (i.e. $<0.1 \%$ ),

138 appear to strongly hinder the adsorption of cationic PPs, suggesting that the cation exchange

139 mechanism between compensating inorganic cations and cationic PPs is limited due to the

140 competition with other compounds for cation exchange (Thiebault et al., 2016b; Wang et al., 2009).

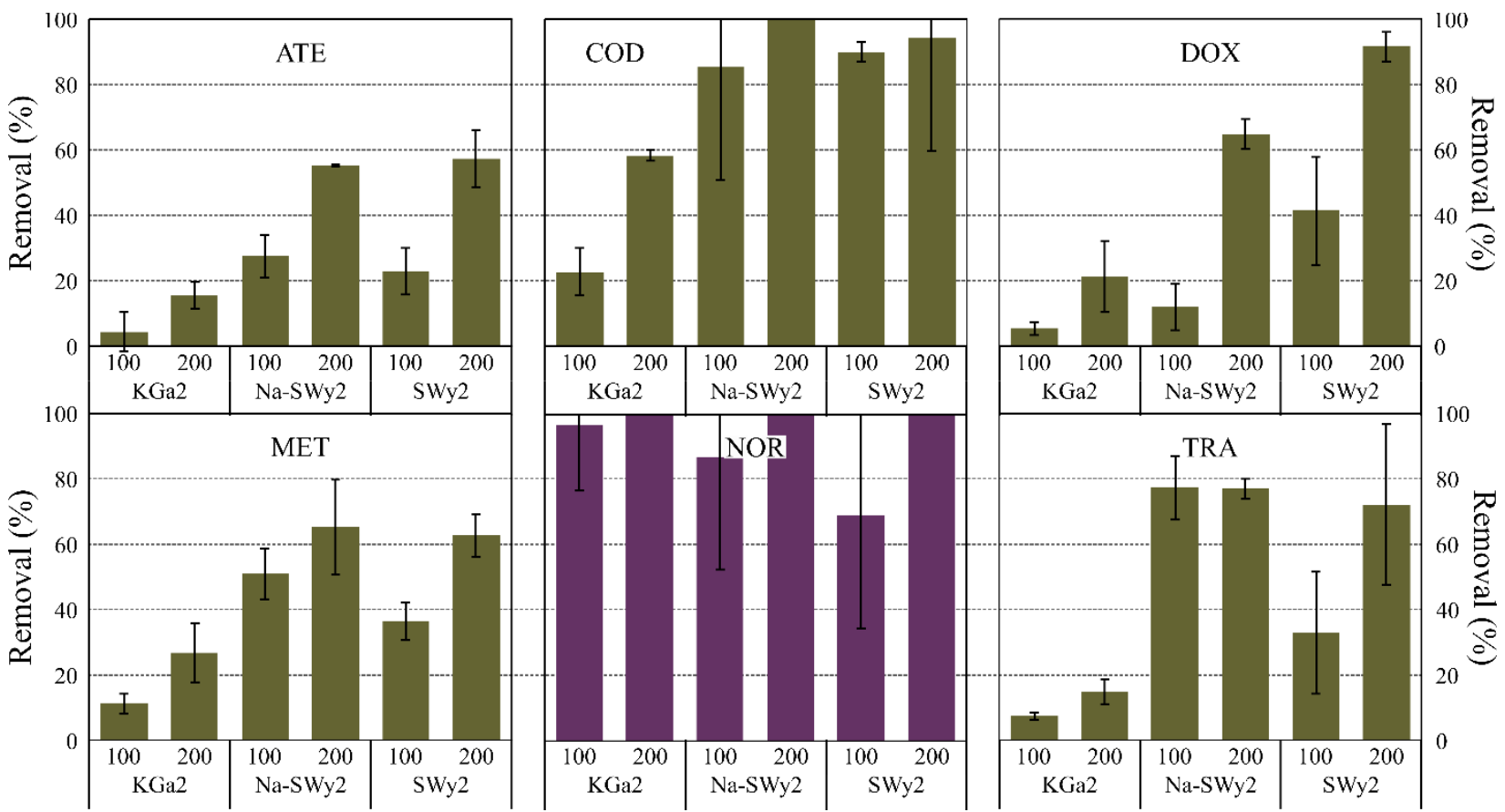

142 Figure 1: Removal percentages of cationic (green bars) and zwitterionic (purple bars) PPs as a function of the mass of adsorbent (i.e. 100 and $200 \mathrm{mg}$ ), $\mathrm{n}=3$

\subsubsection{Neutral PPs}


146 The removal rates of neutral PPs are presented in Figure 2. Various patterns are exhibited as a

147 function of the PP and/or the mass of adsorbent. TMP is a particular case as its speciation in this

$148 \mathrm{pH}$ range is partially neutral and partially protonated (Table 1). As a result, its behavior appears to

149 be intermediate between neutral and cationic molecules. CBZ and OXA are poorly adsorbed onto

150 clay minerals whatever the clay type and the mass of adsorbent; the only significant removal rates

151 displayed are onto SWy2 (Figure 2). DIA is conversely significantly adsorbed onto the three

152 adsorbents with higher removal values on increasing the mass of adsorbent, and higher removal

153 values on SWy2 (i.e. between 5 and 20\%) in comparison with the other two adsorbents (i.e.

154 between 0 and 11\%). This variation between PPs with closely related properties highlights the

155 important role of the starting concentrations of PPs in order to assess their affinity with clay

156 minerals (Thiebault and Boussafir, 2019), and of the affinity of PPs with organic moieties for the

157 adsorption onto clay minerals in effluent solutions (Torrents and Jayasundera, 1997).

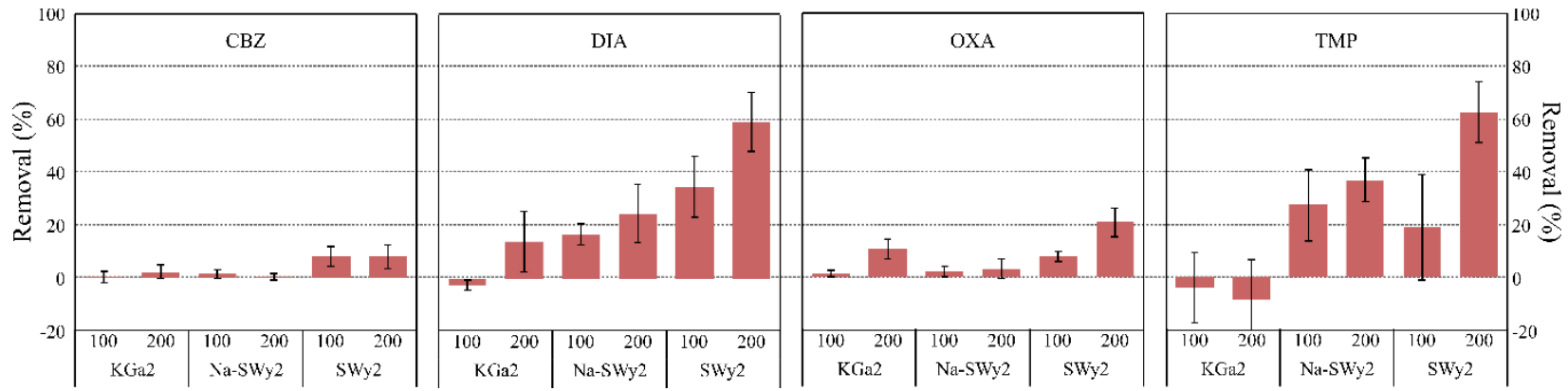

159 Figure 2: Removal percentages of neutral PPs as a function of the mass of adsorbent (i.e. $100 \mathrm{and} 200 \mathrm{mg}$ ), $160 \mathrm{n}=3$

\subsubsection{Anionic PPs}

163 The removal rates of anionic PPs are displayed in Figure 3. Only SUL displays a total removal 164 whatever the adsorbent, mostly due to its very low concentration in the selected effluent (Table 2).

165 The other PPs present a similar pattern with lower removal rates onto KGa2 and higher rates after 166 interaction with SWy2. Weak removal variations are displayed between $\mathrm{KGa} 2$ and Na-SWy2 
167 highlighting the limited affinity of anionic PPs for these two clay minerals. The higher removal 168 rates observed after interaction with $200 \mathrm{mg} \mathrm{SWy2} \mathrm{(i.e.} \mathrm{between} 38$ and $78 \%$ except for SUL) 169 emphasize the impact of the compensating inorganic cations. The only variation between SWy2 170 and Na-SWy2 is the homogenization of the compensating cations in the latter adsorbent. As a 171 result, the significant amount of $\mathrm{Ca}^{2+}$ in SWy2 (i.e. 20\%) appears to significantly enhance the 172 adsorption extent of anionic PPs, or the adsorption of organic moieties which may adsorb such PPs 173 in a second phase.

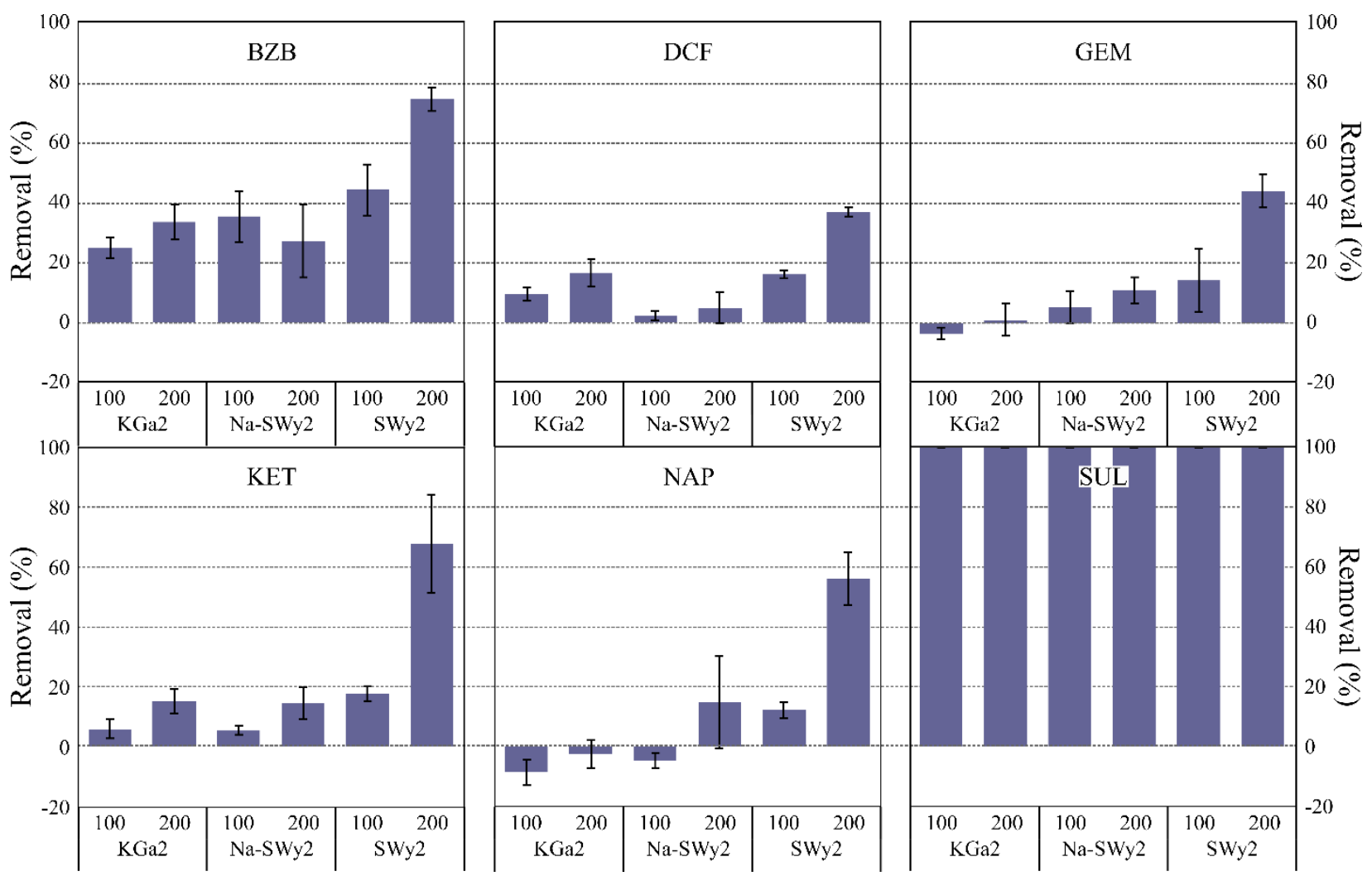

175 Figure 3: Removal percentages of anionic PPs as a function of the mass of adsorbent (i.e. $100 \mathrm{and} 200 \mathrm{mg}$ ), $176 \mathrm{n}=3$

$177 \quad$ 3.3.Adsorbent characterization

178 Prior to characterization, the clay minerals were separated from the supernatant after the interaction

179 experiment by centrifugation. XRD patterns and FTIR spectra exhibited no significant layer 180 expansion or band stretching, respectively (data not shown). 
181 Table 3: Carbon percentages of raw adsorbents (Raw) and after interaction (i.e. 100 and $200 \mathrm{mg}$ ) with the 182 effluent, $\mathrm{n}=3$

\begin{tabular}{llll}
\hline & KGa2 & Na-SWy2 & SWy2 \\
\hline Raw & $0.256 \pm 0.02$ & $0.214 \pm 0.03$ & $0.312 \pm 0.05$ \\
\hline $100 \mathrm{mg}$ & $0.336 \pm 0.03$ & $0.648 \pm 0.04$ & $1.027 \pm 0.05$ \\
\hline $200 \mathrm{mg}$ & $0.341 \pm 0.05$ & $0.581 \pm 0.07$ & $0.959 \pm 0.06$ \\
\hline
\end{tabular}

183

184 The organic carbon content adsorbed onto clay after interaction was estimated from the elemental 185 analyses. This bonded organic carbon can be either PPs or organic complexes present in the WWE.

186 All the clay minerals display an increase in the carbon content in comparison with the initial 187 composition (Table 3). Moreover, due to the weak concentration of PPs in the raw effluents in 188 comparison with the total organic carbon content (i.e. $<0.1 \%$ ), it is highly possible that most of the 189 adsorbed organic carbon was generated by other organic compounds, thus masking the PP 190 contribution to the whole carbon content. The carbon content after interaction ranges from $0.34 \%$

191 (or $0.08 \%$ if we consider the carbon content of the raw adsorbent) for $\mathrm{KGa} 2$ to $~ 1 \%$ (or $0.7 \%$ if

192 we consider the carbon content of the raw adsorbent) for SWy2 (Table 3). On increasing the mass

193 of adsorbent from 100 to $200 \mathrm{mg}$, the carbon content of the adsorbents did not significantly vary,

194 highlighting that the adsorption of organic moieties onto these adsorbents may be controlled by the

195 solid/water partition. Therefore, an increase in the mass of adsorbent proportionally increases the

196 amount of organic carbon adsorbed. From a global point of view, the displayed pattern is equivalent

197 for PP removal and carbon analyses. The adsorption is weak onto KGa2 whereas it is higher onto

198 SWy2, emphasizing the important role of the properties of the adsorbent, and the impact of the 199 inorganic compensating cations.

\subsection{Comparative efficiency of clay minerals}

201 The removal capacity of the three selected clay minerals appears to be enhanced when a higher 202 mass of adsorbent is used. This is consistent with previous studies, which emphasized the 
203 contribution of the solid liquid partition coefficient in the adsorption of non-cationic PPs (Stein et

204 al., 2008). Hence, the higher the solid/liquid ratio of adsorbent, the higher the removal rate.

205 However, significant variations are found in the efficiency of the tested adsorbents. KGa2 presents

206 the lowest adsorption capacities of all the targeted PPs, whatever their charge state. This is probably

207 due to its weak CEC and SSA, limiting the affinity with organic moieties in comparison with

208 montmorillonites. Between SWy2 and Na-SWy2, the adsorption performance of the latter is

209 slightly better for the removal of cationic PPs whereas the opposite pattern is displayed for neutral

210 and anionic PPs. This can be attributed to the fact that the compensating inorganic cations of SWy2

211 are not only $\mathrm{Na}^{+}$, but also $\mathrm{Ca}^{2+}$ in a significant proportion, allowing the formation of cationic

212 bridges with negatively charged organic moieties such as anionic PPs, or organic complexes

213 present in the effluents (Aristilde et al., 2016; Zhang et al., 2019). These results on PPs are

214 confirmed by the elemental analyses, in which SWy2 displays the highest adsorbed amount of

215 carbon. The latter adsorbent, therefore, presents the most suitable adsorption properties for the

216 removal of PPs and potentially other organic contaminants, from WWE.

217 4. Conclusion

218 In this study, the potential of three clay minerals for the removal of PPs from raw WWE was studied

219 for the first time in batch experiments, thereby deepening our understanding of the affinity between

220 such adsorbents and PPs. The results clearly show that among the three adsorbents tested, KGa2

221 presents the lowest adsorption capacity for both PPs and other organic moieties present in the

222 effluent. Secondly, the homogenization of the compensating cations of SWy2 (i.e. Na-SWy2) is

223 not favorable for the adsorption of neutral and anionic PPs, which may interact with $\mathrm{Ca}^{2+}$ cations

224 through cationic bridges. This can be considered as a positive outcome, given the need to use as

225 raw as possible material. Hence, SWy2 presents suitable adsorption properties in batch experiments 
for the removal of PPs from wastewater effluents. Finally, this work demonstrates that, in contrast

to many studies on idealized solutions, the organic compounds present in raw WWE contribute to

experiments conducted in pure water. These adsorbed organic moieties increase the hydrophobicity

230 of the adsorbent and the number of adsorption sites. However, further studies remain necessary in

231 order to transfer these results from batch experiments to dynamic ones, closer to the design of a

232 field solution.

\section{Acknowledgements}

234 This study received financial support from the HArPE Project (2012-00073536) funded by the

Région Centre Val de Loire. M. Hatton is gratefully thanked for carbon elemental analyses.

\section{References}

Aristilde, L., Lanson, B., Miéhé-Brendlé, J., Marichal, C., Charlet, L., 2016. Enhanced interlayer trapping of a tetracycline antibiotic within montmorillonite layers in the presence of $\mathrm{Ca}$ and Mg. J. Colloid Interface Sci. 464, 153-159. https://doi.org/10.1016/j.jcis.2015.11.027

Baker, D.R., Barron, L., Kasprzyk-Hordern, B., 2014. Illicit and pharmaceutical drug consumption estimated via wastewater analysis. Part A: Chemical analysis and drug use estimates. Sci. Total Environ. 487, 629-641. https://doi.org/10.1016/j.scitotenv.2013.11.107

Chemspider Database, n.d. http:Ilchemspider.com [WWW Document]. URL http://www.chemspider.com/ (accessed 5.16.19).

Chen, Y., Zhou, A., Liu, B., Liang, J., 2010. Tramadol hydrochloride/montmorillonite composite: Preparation and controlled drug release. Appl. Clay Sci. 49, 108-112. https://doi.org/10.1016/j.clay.2010.04.011

Chipera, S.J., Bish, D.L., 2001. Baseline studies of the clay minerals society source clays: Powder X-ray diffraction analyses. Clays Clay Miner. 49, 398-409.

Choi, P.M., Tscharke, B.J., Donner, E., O’Brien, J.W., Grant, S.C., Kaserzon, S.L., Mackie, R., O’Malley, E., Crosbie, N.D., Thomas, K.V., Mueller, J.F., 2018. Wastewater-based epidemiology biomarkers: Past, present and future. TrAC Trends Anal. Chem. 105, 453469. https://doi.org/10.1016/j.trac.2018.06.004

Cuthbertson, A.A., Kimura, S.Y., Liberatore, H.K., Summers, R.S., Knappe, D.R.U., Stanford, B.D., Maness, J.C., Mulhern, R.E., Selbes, M., Richardson, S.D., 2019. Does Granular Activated Carbon with Chlorination Produce Safer Drinking Water? From Disinfection Byproducts and Total Organic Halogen to Calculated Toxicity. Environ. Sci. Technol. https://doi.org/10.1021/acs.est.9b00023

da Silva, B.F., Jelic, A., López-Serna, R., Mozeto, A.A., Petrovic, M., Barceló, D., 2011. Occurrence and distribution of pharmaceuticals in surface water, suspended solids and 
sediments of the Ebro river basin, Spain. Chemosphere 85, 1331-1339. https://doi.org/10.1016/j.chemosphere.2011.07.051

de Andrade, J.R., Oliveira, M.F., da Silva, M.G.C., Vieira, M.G.A., 2018. Adsorption of pharmaceuticals from water and wastewater using nonconventional low-cost materials: a review. Ind. Eng. Chem. Res. 57, 3103-3127. https://doi.org/10.1021/acs.iecr.7b05137

de Oliveira, T., Guégan, R., Thiebault, T., Milbeau, C.L., Muller, F., Teixeira, V., Giovanela, M., Boussafir, M., 2017. Adsorption of diclofenac onto organoclays: Effects of surfactant and environmental ( $\mathrm{pH}$ and temperature) conditions. J. Hazard. Mater. 323, Part A, 558-566. https://doi.org/10.1016/j.jhazmat.2016.05.001

DrugBank [WWW Document], n.d. URL http://www.drugbank.ca/ (accessed 5.16.19).

Gao, J., Pedersen, J.A., 2005. Adsorption of sulfonamide antimicrobial agents to clay minerals. Environ. Sci. Technol. 39, 9509-9516. https://doi.org/10.1021/es050644c

Grandclément, C., Seyssiecq, I., Piram, A., Wong-Wah-Chung, P., Vanot, G., Tiliacos, N., Roche, N., Doumenq, P., 2017. From the conventional biological wastewater treatment to hybrid processes, the evaluation of organic micropollutant removal: A review. Water Res. 111, 297-317. https://doi.org/10.1016/j.watres.2017.01.005

Le Forestier, L., Muller, F., Villieras, F., Pelletier, M., 2010. Textural and hydration properties of a synthetic montmorillonite compared with a natural Na-exchanged clay analogue. Appl. Clay Sci. 48, 18-25. https://doi.org/10.1016/j.clay.2009.11.038

Lv, G., Stockwell, C., Niles, J., Minegar, S., Li, Z., Jiang, W.-T., 2013. Uptake and retention of amitriptyline by kaolinite. J. Colloid Interface Sci. 411, 198-203. https://doi.org/10.1016/j.jcis.2013.08.026

Paing, J., Voisin, J., 2005. Vertical flow constructed wetlands for municipal wastewater and septage treatment in French rural area. Water Sci. Technol. 51, 145-155. https://doi.org/10.2166/wst.2005.0306

Patel, M., Kumar, R., Kishor, K., Mlsna, T., Pittman, C.U., Mohan, D., 2019. Pharmaceuticals of Emerging Concern in Aquatic Systems: Chemistry, Occurrence, Effects, and Removal Methods. Chem. Rev. 119, 3510-3673. https://doi.org/10.1021/acs.chemrev.8b00299

Petrie, B., Barden, R., Kasprzyk-Hordern, B., 2015. A review on emerging contaminants in wastewaters and the environment: Current knowledge, understudied areas and recommendations for future monitoring. Water Res. 72, 3-27. https://doi.org/10.1016/j.watres.2014.08.053

Richmond, E.K., Rosi, E.J., Walters, D.M., Fick, J., Hamilton, S.K., Brodin, T., Sundelin, A., Grace, M.R., 2018. A diverse suite of pharmaceuticals contaminates stream and riparian food webs. Nat. Commun. 9, 4491. https://doi.org/10.1038/s41467-018-06822-w

Saaristo, M., Brodin, T., Balshine, S., Bertram, M.G., Brooks, B.W., Ehlman, S.M., McCallum, E.S., Sih, A., Sundin, J., Wong, B.B.M., Arnold K. E., 2018. Direct and indirect effects of chemical contaminants on the behaviour, ecology and evolution of wildlife. Proc. R. Soc. B Biol. Sci. 285, 20181297. https://doi.org/10.1098/rspb.2018.1297

Stein, K., Ramil, M., Fink, G., Sander, M., Ternes, T.A., 2008. Analysis and sorption of psychoactive drugs onto sediment. Environ. Sci. Technol. 42, 6415-6423. https://doi.org/10.1021/es702959a

Thiebault, T., 2019. Raw and modified clays and clay minerals for the removal of pharmaceutical products from aqueous solutions: state of the art and future perspectives. Crit. Rev. Environ. Sci. Technol. https://doi.org/10.1080/10643389.2019.1663065 
306

307

308

309

310

311

312

313

314

315

316

317

318

319

320

321

322

323

324

325

326

327

328

329

330

331

332

333

334

335

336

337

338

339

340

341

342

343

344

345

346

Thiebault, T., Boussafir, M., 2019. Adsorption mechanisms of psychoactive drugs onto montmorillonite. Colloid Interface Sci. Commun. 30, 100183. https://doi.org/10.1016/j.colcom.2019.100183

Thiebault, T., Boussafir, M., Guégan, R., Le Milbeau, C., Le Forestier, L., 2016a. Clayey-sand filter for the removal of pharmaceuticals from wastewater effluent: percolation experiments. Environ. Sci. Water Res. Technol. 2, 529-538. https://doi.org/10.1039/C6EW00034G

Thiebault, T., Boussafir, M., Le Forestier, L., Le Milbeau, C., Monnin, L., Guégan, R., 2016b. Competitive adsorption of a pool of pharmaceuticals onto a raw clay mineral. RSC Adv. 6, 65257-65265. https://doi.org/10.1039/C6RA10655B

Thiebault, T., Fougère, L., Destandau, E., Réty, M., Jacob, J., 2019. Impact of meteorological and social events on human-excreted contaminant loads in raw wastewater: From daily to weekly dynamics. Chemosphere 230, 107-116. https://doi.org/10.1016/j.chemosphere.2019.04.221

Thiebault, T., Guégan, R., Boussafir, M., 2015. Adsorption mechanisms of emerging micropollutants with a clay mineral: Case of tramadol and doxepine pharmaceutical products. J. Colloid Interface Sci. 453, 1-8. https://doi.org/10.1016/j.jcis.2015.04.029

Torrents, A., Jayasundera, S., 1997. The sorption of nonionic pesticides onto clays and the influence of natural organic carbon. Chemosphere 35, 1549-1565. https://doi.org/10.1016/S0045-6535(97)00206-3

Wang, C., Ding, Y., Teppen, B.J., Boyd, S.A., Song, C., Li, H., 2009. Role of interlayer hydration in lincomycin sorption by smectite clays. Environ. Sci. Technol. 43, 6171-6176. https://doi.org/10.1021/es900760m

Wong, S., Ngadi, N., Inuwa, I.M., Hassan, O., 2018. Recent advances in applications of activated carbon from biowaste for wastewater treatment: A short review. J. Clean. Prod. 175, 361375. https://doi.org/10.1016/j.jclepro.2017.12.059

Wu, M., Zhao, S., Tang, M., Jing, R., Shao, Y., Liu, X., Dong, Y., Li, M., Liao, Q., Lv, G., Zhang, Q., Meng, Z., Liu, A., 2019. Adsorption of sulfamethoxazole and tetracycline on montmorillonite in single and binary systems. Colloids Surf. Physicochem. Eng. Asp. 575, 264-270. https://doi.org/10.1016/j.colsurfa.2019.05.025

Zhang, W., Ding, Y., Boyd, S.A., Teppen, B.J., Li, H., 2010. Sorption and desorption of carbamazepine from water by smectite clays. Chemosphere 81, 954-960. https://doi.org/10.1016/j.chemosphere.2010.07.053

Zhang, Y., Lu, M., Su, Z., Wang, J., Tu, Y., Chen, X., Cao, C., Gu, F., Liu, S., Jiang, T., 2019. Interfacial reaction between humic acid and Ca-Montmorillonite: Application in the preparation of a novel pellet binder. Appl. Clay Sci. 180, 105177. https://doi.org/10.1016/j.clay.2019.105177

Zhu, R., Chen, Q., Zhou, Q., Xi, Y., Zhu, J., He, H., 2016. Adsorbents based on montmorillonite for contaminant removal from water: A review. Appl. Clay Sci. 123, 239-258. https://doi.org/10.1016/j.clay.2015.12.024 